Bull. Chem. Soc. Ethiop. 2019, 33(1), 169-182.

ISSN 1011-3924

(c) 2019 Chemical Society of Ethiopia and The Authors

Printed in Ethiopia

DOI: https://dx.doi.org/10.4314/bcse.v33i1.17

\title{
A MATHEMATICAL MODEL FOR DETERMINING THE BEST PROCESS CONDITIONS FOR AVERAGE MOLECULAR WEIGHT AND MELT FLOW INDEX OF POLYPROPYLENE
}

\author{
Gholam Hossain Varshouee ${ }^{1}$, Amir Heydarinasab ${ }^{1 *}$, Ali Vaziri ${ }^{1}$ and Behrooz Roozbahani ${ }^{2}$ \\ ${ }^{1}$ Department of Petroleum and Chemical Engineering, Science and Research Branch, Islamic \\ Azad University, Tehran, Iran \\ ${ }^{2}$ Department of Chemical and Biomolecular Engineering, Research Associates of Rice \\ University, USA
}

(Received June 24, 2018; Revised January 9, 2019; Accepted January 17, 2019)

\begin{abstract}
The present work describes a mathematical model based on a population balance approach for determining the effect of the reaction temperature and hydrogen amount on the vital final product properties including average molecular weight and polydispersity index and flow index of polypropylene and also the profile rate of the polymerization. The aim of this study was to find the best operating condition through a model which is validated by the experimental data. The software program was coded in MATLAB/SIMULINK. The model profile rates compared with the experimental results to show the accuracy of the model. In this study, it was concluded that increasing the reaction temperature until a certain limit is useful and improve some indices of the final product and after that rising the reaction temperature has a harmful effect on the indices. Exactly the same issue is true in the case of increasing the amount of hydrogen.
\end{abstract}

KEY WORDS: Mathematical modeling, Propylene polymerization, Melt flow index, Population balance, Average molecular weight, hydrogen

\section{INTRODUCTION}

Polypropylene is one of the most valuable polyolefin products which having excellent physicalmechanical properties and relatively low prices. The final product properties categorize its applications and highly depend on the kinetics of the reaction. Owing to the complexity of the catalyst kinetics and despite a long history of consuming Ziegler-Natta catalyst more than sixty years, the polymerization performance still remains unknown and unclear $[1,2]$.

The crucial indices of the final product properties are comprising of flow index (MFI); number and weight average molecular weight ( $\mathrm{Mw}$ and $\mathrm{Mn}$ ) which are classified the polymer applications. Among them, the average molecular weight is the most significant index, which must be precisely controlled. Weight average molecular weight depends strongly on the polymerization kinetics and the polymerization rate profiles (Rpt). For controlling the average molecular weight, it is necessary to find a clear image of the behavior of the polymerization system as a function of operating conditions such the reaction temperature and hydrogen amount in the polymerization system. Due to the complexity of the kinetics and a large number of polymerization reactions, only a validated mathematical model might approach us to the aim.

Varshouee et al. focused on providing a validated model that able to predict polymerization profile graphically and proposed a model to show the percentage of the total existing catalyst sites which be activated by the used hydrogen amount [3]. In the following, they investigated the effect of the reaction temperature and the hydrogen amount on the deactivation constant $\left(\mathrm{K}_{\mathrm{d}}\right)$ and the yield of the catalyst used and also evaluated the variation of the melt flow index of the final product by imperial equation in absence of hydrogen [4]. Afterward, they decided to expand their model to cover the above mentioned existing gap and also proposing a new model

*Corresponding author. E-mail: a.heidarinasab@srbiau.ac.ir

This work is licensed under the Creative Commons Attribution 4.0 International License 
to predict the variations of melt flow index with hydrogen amounts. This article is the result of the decision. This study presents a validated model based on a kinetic model which is able to make a profound sense of the polymerization performance. The main advantages of this model are that it can easily estimate the final product properties such as number and eight average molecular weight (Mw and Mn), flow index (MFI) and determining the best process conditions of the polymerization recipe namely the reaction temperature and hydrogen amount in the polymerization system.

The most previous studies in this regard have focused on an experimental approach, whereas this method is not reliable, because of their results heavily dependent on test and laboratory conditions. The other constraint of the method is the different type of the catalyst used that their results cannot be used for each other [5-7]. Reginato et al. modeled an industrial-scale loop reactor by assuming that a non-ideal continuous stirred tank model can be used instead of loop reactor model, they claimed that their model was validated by commercial plant data [2]. Al-haj Ali et al. proposed a generalized model for hydrogen response based on the dormant site theory in bulk propylene polymerization but they used an experimental profile rate of the polymerization in their study. There was no validated model which might be able to predict the profile rate of the polymerization and the vital indices of final product properties such as average molecular weight mathematically at the same time [5].

Although some other researchers have endeavoured on the propylene polymerization modeling, the existing gap still remains. Most of their models were proposed based on mathematical calculations without validation with experimental data. Their studies have only focused on a loop or fluidized-bed reactors (FBRs) in bulk or gas phase polymerization [2, 810]. Yang et al. have modeled a commercial loop propylene polymerization reactor in bulk media without paying attention to kinetic study and final product properties [11]. Thereafter, another researcher has been attempted to model a multi-scale polypropylene reactor in the fluidized bed reactor (FBR) using moment equations [12]. In 2016, Kim et al. have also simulated Sheripol technology in bulk polymerization without paying attention to some final product properties such as average molecular weight and polydispersity as well [13].

This study proposes a validated model to determine some crucial indices such as melt flow index (MFI); number and weight average molecular weight (Mw and $\mathrm{Mn}$ ) as the best way. The model is able to show the profile rate of the polymerization graphically and also able to determine the best condition of the polymerization, namely the best reaction temperature and hydrogen amount in the polymerization system.

By using the model, the chemists, who are working on the catalyst preparation could improve their new catalyst. In addition, the model might be beneficial for the process engineers to replace new catalyst in the commercial reactor without risk and hazard; and also he can design a new recipe for new economical grades or a tailor-made polymer in order to a certain application by using the available catalyst.

Population balance approach (moment balance method) was selected as the modeling approach for slurry polymerization. The advantages of the approach can be listed as follows: (1) The profile rate of the polymerization can be calculated and plotted with acceptable accuracy and (2) The vital final property such as average molecular weight is obtained directly from kinetic equations.

The software program was coded in MATLAB/SIMULINK. The model was validated by experimental data from a lab scale semi-batch reactor with an acceptable margin of error. For this study, it is concluded that $70{ }^{\circ} \mathrm{C}$ and $18 \mathrm{mg}$ of hydrogen amount are the best conditions for the catalyst used in the polymerization system.

\section{EXPERIMENTAL}

The 4th generation of spherical $\mathrm{MgCl}_{2}$ supported Ziegler-Natta catalyst containing $3.6 \mathrm{wt} \% \mathrm{Ti}$ and Di-isobutyl phthalate (DIBP) as internal donor supplied by Sudchemie, Germany. Tri-ethyl- 
aluminum (TEA of $98 \%$ purity) from Merck, Germany, diluted in n-heptane was used as a cocatalyst and the so-called external donor (cyclohexyl methyl dimethoxy silane) were purchased from Merck and was used without further purification. Polymer-grade propylene was provided from Shazand Petrochemical company in Iran and was used as received. Hydrogen and nitrogen used were of $>99.999 \%$ purity. Nitrogen was further purified by passing over beds of absorbents. A typical polymerization procedure exists for reactor preparation, polymerization, and discharge. The detailed procedure of the polymerization was according to the reference [3, 4].

Experimental the profile polymerization curve (Rpt) curves come for setup monitor, then the molecular weight of products are measured by gel permeation chromatography (GPC), employing an Agilent PL-220 model with TSK columns at $155^{\circ} \mathrm{C}$ using 1,2,4-trichlorobenzene as a solvent. The GPC is calibrated with the narrow molecular weight distribution polystyrene standard as a reference. The melt flow index (MFI) of samples is evaluated according to ASTM 1238 at the temperature of $230^{\circ} \mathrm{C}$ and load of $2.16 \mathrm{~kg}$.

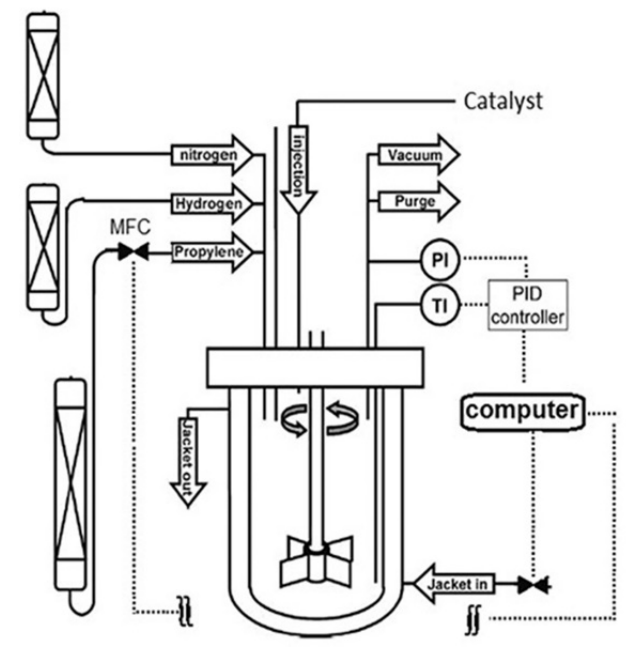

Figure 1. Simplified schematic of the reactor system [4].

\section{Modeling description}

\section{Assumptions}

The following modeling assumptions are considered: (1) It was supposed that propylene polymerization was carried out in the amorphous phase and amorphous phase concentrations during polypropylene polymerization is at the thermodynamic equilibrium condition that obeys from Sanchez and Lacombe Equation(SLE) [14] for calculating the amount of $\mathrm{X}=\mathrm{CH} / \mathrm{Cm}$, the hydrogen molar ratio. (2) It was assumed that $\gamma 1=\gamma 2=\ldots . .=\gamma \mathrm{NC}$, where $\gamma$ is equilibrium constant and $\mathrm{NC}$ is a number of solvent in slurry phase components [2]. (3) The reaction temperature, pressure, and monomer concentration were kept constant during the polymerization process. (4) The resistance of both mass and heat transfer and the diffusion effect of the reactants were ignored. (5) It was assumed that the propagation constant is independent of the length of the growing polymer chain. (6) Using "dormant sites theory" for activating catalyst by hydrogen concentration $[5,10]$.

Bull. Chem. Soc. Ethiop. 2019, 33(1) 


\section{Formulation}

The used reaction equations in this model are listed in Table 2. The ODE mass balance equations in the model are as follows:

$$
\begin{aligned}
& \frac{d C_{j, R}}{d t}=\left[\frac{Q_{f} C_{j, f}}{V_{R}}\right] \text { feed(input) }-\left[\frac{(\eta / \zeta) Q_{0} C_{j, R}}{V_{R}}\right]_{\text {output }}+R_{j} \\
& C_{j, R}=\frac{\text { Mole of } j}{\text { Total Volume }} \quad \text { for } \mathrm{j}=1,2, \ldots, \mathrm{NC} \\
& \eta_{j}=\frac{C_{j, a}}{C_{j, l}} \\
& \text { for } \mathrm{j}=1,2, \ldots, \mathrm{NC} \\
& \zeta_{j}=\frac{C_{j, o}}{C_{j, R}}=\frac{\rho_{0}}{\rho_{R}} \cdot D_{f} \\
& (\eta / \zeta)=\left\{\begin{array}{l}
\eta \text { for liquid phase components } \\
\zeta \text { for solid phase components }
\end{array}\right.
\end{aligned}
$$

$\mathrm{Q}_{\mathrm{f}}, \mathrm{Q}_{0}$, and $\mathrm{Q}_{\mathrm{R}}$ are feed volumetric flow rate, reactor-output volumetric flow rate and volumetric recirculation flow rate in respectively. In which $\mathrm{V}_{\mathrm{R}}$ and $\mathrm{Rj}$ are defined as reactor volume and $\mathrm{j}$ component reaction rate in equation 1.

Since the model is a semi-batch process and assumed constant monomer concentration during the polymerization, the input and output terms are eliminated (Qf and Q0) then the terms of $\eta$ and $\zeta$ are meaningless in this study. Table 1 shows possible reactions with their rate equations in the polymerization reactor. The Concentration variations with time used in modeling are as follows:

$C_{j}=C_{H}, C_{A}, C_{E}, C_{M i}, C_{B}, C_{S}, C_{c a t}, P_{\mathbf{0}}^{k}, \mu_{\mathbf{0}}^{k}, \mu_{\mathbf{1}}^{k}, \lambda_{\mathbf{0}}^{k}, \lambda_{\mathbf{1}}^{k}, \lambda_{\mathbf{2}}^{k}$

Where: $\mathrm{k}$ is site number of the catalyst.

In this study, it is supposed that the catalyst has mono-site, and then $\mathrm{k}$ is equal to one. Here, $\mathrm{C}_{\mathrm{H}}$, $\mathrm{C}_{\mathrm{A}}, \mathrm{C}_{\mathrm{E}}, \mathrm{C}_{\mathrm{Mi}}, \mathrm{C}_{\mathrm{B}}, \mathrm{C}_{\mathrm{S}}, \mathrm{Ccat}$, and $\mathrm{P}_{0}$ is the concentration of hydrogen, co-catalyst (aluminum alkyl), electron donor, monomer, poison, site transfer, catalyst and potential site in the polymerization in respectively. Table 2 is listed the component rate equations and moment equations have been used in the model. The final product properties of polypropylene can be estimated by the moment equations. The basic polymer properties, called as end-use properties, are four items; Number average molecular weight $(\mathrm{Mn})$, weight average molecular weight $(\mathrm{Mw})$, melt flow index (MFI) and polydispersity index (PDI). The relationship between the moment and these indices are defined by the following equations:

$$
\begin{aligned}
& \overline{M_{n}}=\sum_{K=1}^{N s} \sum_{i=1}^{N m} \frac{\lambda_{\delta_{i}}^{k}}{\lambda_{0}^{k}} \overline{M_{i}} \\
& \overline{M_{w}}=\lambda_{2} \cdot \sum_{k=1}^{N s} \lambda_{0}^{k} \overline{M_{n}} \\
& \text { Then : } \quad D P I=\frac{\left.\overline{\left(\sum_{K=1}^{N s} \sum_{i=1}^{N m}\right.} \lambda_{\delta_{i}}^{k}\right)^{2}}{\overline{M_{n}}}
\end{aligned}
$$


Table 1. The probable reactions and their rate equations in propylene polymerization used in the model [2]

\begin{tabular}{|c|c|c|c|}
\hline Reaction step & Component & Reaction & Rate equation \\
\hline \multirow[t]{3}{*}{ Site activation } & Hydrogen & $C_{p}+H_{2} \rightarrow P_{\mathbf{0}}^{K}$ & $R_{a H}^{K}=k_{a H}^{k} C_{p} C_{H, a}^{O} O_{a H}^{K}$ \\
\hline & Al-alkyl & $C_{p}+A \rightarrow P_{\mathbf{0}}^{K}+B$ & $R_{a A}^{K}=k_{a A}^{k} C_{p} C_{A, a}^{O A}$ \\
\hline & Monomer $i$ & $C_{p}+M_{i} \rightarrow P_{\mathbf{0}}^{K}+M_{i}$ & $R_{a M i}^{K}=k_{a M i}^{k} C_{p} C_{M i}^{O M i}$ \\
\hline Chain initiation & Monomer $i$ & $P_{\mathbf{0}}^{k}+M_{i} \rightarrow P_{\delta_{i}, i}^{K}$ & $R_{P \mathbf{0} i}^{K}=k_{P \mathbf{0} i}^{k} P_{\mathbf{0}}^{K} C_{M_{i}, a}$ \\
\hline $\begin{array}{l}\text { Chain } \\
\text { propagation }\end{array}$ & Monomer $j$ & 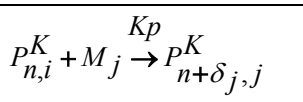 & $R_{P j i}^{K}=k_{P j i}^{k} P_{n, j}^{K} C_{M_{j}, a}$ \\
\hline \multirow[t]{2}{*}{ Chain transfer } & Hydrogen & $P_{n, i}^{K}+H_{\mathbf{2}} \underset{\rightarrow}{K h} P_{\mathbf{0}}^{K}+D_{n}^{k}$ & $R_{c H i}^{K, n}=k_{c H i}^{k} P_{n, i}^{K} C_{H, a}^{O} O_{c H i}^{K}$ \\
\hline & Monomer $j$ & $P_{n, i}^{K}+M_{j} \stackrel{K m}{\rightarrow} P_{\delta_{j}, j}^{K}+D_{n}^{k}$ & $R_{c M_{j i}}^{K, n}=k_{c M_{j i}}^{k} P_{n, i}^{K} C_{j, a}^{O_{c M j, i}^{K}}$ \\
\hline \multirow[t]{5}{*}{$\begin{array}{l}\text { Site } \\
\text { deactivation }\end{array}$} & Hydrogen & $P_{n, i}^{K}+H_{2} \rightarrow C_{d}+D_{n}^{k}$ & $R_{a H i}^{K, n}=k_{d H}^{k} P_{n, i}^{K} C_{H, a}^{O_{d H}^{K}}$ \\
\hline & & $P_{\mathbf{0}}^{K}+H_{2} \rightarrow C_{d}$ & $R_{d H \mathbf{0}}^{K}=k_{d H}^{k} P_{\mathbf{0}}^{K} C_{H, a}^{O} O_{d H}^{K}$ \\
\hline & Al-alkyl & $P_{n, i}^{K}+A \rightarrow C_{d}+D_{n}^{k}$ & $R_{d A i}^{K, n}=k_{d A}^{k} P_{n, i}^{K} C_{A, a}^{O} O_{d A}^{K}$ \\
\hline & Spontaneous & $P_{n, i}^{K} \rightarrow C_{d}+D_{n}^{k}$ & $R_{d S p i}^{K, n}=k_{d S p}^{k} P_{n, i}^{K}$ \\
\hline & & $P_{\mathbf{0}}^{K} \rightarrow C_{d}$ & $R_{d S p \mathbf{0}}^{K}=k_{d S p}^{k} P_{\mathbf{0}}^{K}$ \\
\hline
\end{tabular}

Melt flow index

The melt flow index (MFI) is one of the most important of polymer rheology index, Which is an indicator to determine the application polymer. It has inversely proportional toWeight average molecular weight. A power-law-Equation based on Mark-Houwink model was suggested as a model that is able to calculate MFI as follows [2]:

$M F I=a \cdot\left(\overline{M_{w}}\right) b$

If $X=0$ (i.e. no hydrogen in system; as defined by Eq (6)), $a$ and $b$ parameters which should be obtained according to experimental data. The equation is fairly fitted only in the absence of hydrogen in the polymerization system. In the presence of hydrogen, some other researchers such as McAuley and MacGregor for polyethylene and Wang et al. for polypropylene suggested another model for predicting MFI [16-17]:

$\mathrm{X}=\mathrm{CH}_{2} / \mathrm{Cm} \quad \mathrm{X}$ is the hydrogen-monomer molar ratio:

$\log (\mathrm{MFI})=\alpha+\beta \cdot \log (\mathrm{X})+\gamma \cdot \log (\mathrm{T}) \quad$ If $\mathrm{X}=0$ (i.e. hydrogen exists in system)

Where $\mathrm{T}$ is the reaction temperature $\left({ }^{\circ} \mathrm{C}\right) ; \alpha, \beta$ and $\gamma$ are equation constants such as before should be determined by experimental data. The amount of the $\alpha, \beta$, and $\gamma$ for this study will be inserted in results and discussion as well. 
Table 2. The component rate and moment equations used in the model [2].

\begin{tabular}{|c|c|}
\hline Hydrogen & $R_{H}=-\sum_{K=1}^{N s}\left[R_{a H}^{k}+R_{r H}^{k}+R_{d H 0}^{k}+\sum_{i=1}^{N m} \sum_{n=\delta_{i}}^{\infty}\left(R_{c h i}^{k, n}+R_{d H i}^{k, n}\right)\right]$ \\
\hline Cocatalyst & $R_{A}=-\sum_{K=1}^{N s}\left[R_{a A}^{k}+R_{d A 0}^{k}+\sum_{i=1}^{N m} \sum_{n=\delta_{i}}^{\infty} R_{d A i}^{k, n}\right]-R_{e A}$ \\
\hline Electron donor & $R_{E}=-\sum_{K=1}^{N s}\left[R_{d E 0}^{k}+\sum_{\substack{l=1 \\
l \neq K}}^{N s} R_{t E 0}^{k l}+\sum_{i=1}^{N m} \sum_{n=\delta}^{\infty}\left(\sum_{\substack{l=1 \\
l \neq K}}^{N s}\left(R_{t E i}^{l k, n}+R_{d E i}^{k, n}\right)\right]-R_{e E}\right.$ \\
\hline Poison & $R_{X}=-\sum_{K=1}^{N s}\left[R_{d X 0}^{k}+\sum_{i=1}^{N m} \sum_{n=\delta_{i}}^{\infty} R_{d X i}^{k, n}\right]-R_{e E}-R_{e A}$ \\
\hline Potential sites & $R_{C p}=-\sum_{K=1}^{N s}\left(R_{a H}^{k}+R_{a A}^{k}+R_{a S p}^{k}+\sum_{i=1}^{N m} R_{a M_{i}}^{k}\right)$ \\
\hline Dead sites & $\alpha_{i}^{k}=k_{c H i}^{k} C_{H, a}^{O_{c t i}^{k}}+k_{c s p i}^{k}+\sum_{j=1}^{N m} k_{c M j, i}^{k} C_{M j, a}+\sum_{\substack{l=1 \\
l \neq K}}^{N s}\left(k_{t E i}^{k l} C_{E, a}^{O_{i, a}^{k H}}+k_{t S p p i}^{k l}\right)+k_{d H i}^{k} C_{H, a}^{O_{d H A}^{k}}+k_{d A i}^{k} C_{A, a}^{O_{d, a}^{k}}$ \\
\hline Monomer & $\left.R_{M i}=-\sum_{K=\mathbf{1}}^{N s} R_{P 0 i}^{k}+\sum_{j=1}^{N m} \sum_{n=\delta}^{\infty}\left(R_{P i j}^{k, n}+R_{c M i, j}^{k, n}\right)\right]$ \\
\hline & Moments equations \\
\hline Live polymer & $R_{P_{n, i}^{k}}=\delta\left(n-\delta_{i}\right)\left[R_{P 0 i}^{k}+\sum_{j=\mathbf{1}}^{N m} \sum_{m=\delta i}^{\infty} R_{c M i, j}^{k, m}\right]+\sum_{j=\mathbf{1}}^{N m} k_{p i j}^{k} C_{M i, a} P_{n-\delta_{i}, j}^{k}-\sum_{j=\mathbf{1}}^{N m} k_{p i j}^{k} C_{M}$ \\
\hline Dead polymer & $\begin{array}{l}R_{D_{n,}^{k}}=\sum_{i=1}^{N m} \alpha_{i}^{k} P_{n, i}^{i} \quad \text { where } \\
\alpha_{i}^{k}=k_{c H i}^{k} C_{H, a}^{O_{t h i}^{k}}+k_{c S p i}^{k}+\sum_{j=1}^{N m} k_{c M j, i}^{k} C_{M j, a}+\sum_{\substack{l=1 \\
l \neq K}}^{N s}\left(k_{t E i}^{k l} C_{E, a}^{O_{t:}^{k l}}+k_{t S p i}^{k l}\right)+k_{d H i}^{k} C_{H, a}^{O_{d H}^{k}}+k_{d A i}^{k} C_{A, a}^{O_{d, a}^{k}}\end{array}$ \\
\hline Live moment & $\mu_{\delta_{i, i}}^{k}=\sum_{n=1}^{\infty} n^{\delta_{i}} P_{n, i}^{k}$ \\
\hline Bulk moment & $\lambda_{\delta_{i}}^{k}=\sum_{n=\delta_{i}}^{\infty}\left(\sum_{i=1}^{N m} P_{n, i}^{k}+D_{n}^{k}\right)$ \\
\hline $\begin{array}{l}\text { Zero-order; live polymer } \\
\text { moments }\end{array}$ & $\begin{array}{l}R_{\mu_{\mathbf{0}, i}^{K}}^{K}=R_{P \mathbf{0} i}^{k}+\sum_{j=\mathbf{1}}^{N m} k_{c M_{i}, j}^{k} C_{M i, a} \mu_{\mathbf{0}, J}^{k}-\alpha_{i}^{k} \mu_{\mathbf{0}, J}^{k} \\
\left.+\sum_{j=\mathbf{1}}^{N m} k_{p i j}^{k} C_{M i, a} \mu_{\mathbf{0}, J}^{k}-k_{p j i}^{k} C_{M j, a} \mu_{\mathbf{0}, i}^{k}\right]\end{array}$ \\
\hline $\begin{array}{l}\text { First-order; live polymer } \\
\text { moments }\end{array}$ & $R_{\mu_{\delta_{l}}^{K}}=\sum_{i=1}^{N m} \delta(i-l)\left[R_{P 0 i}^{k}+\sum_{j=1}^{N m} k_{c M_{i}, j}^{k} C_{M i, a} \mu_{0, J}^{k}\right]-\sum_{i=1}^{N m} \alpha_{i}^{k} \mu_{\delta_{l}, i}^{k}+\sum_{i=1}^{N m} \sum_{j=1}^{N m} k_{p i j}^{k} C_{M i, a} \delta($ \\
\hline $\begin{array}{l}\text { Zero-order; bulk polymer } \\
\text { moments }\end{array}$ & $R_{\lambda_{0}^{K}}=\sum_{i=1}^{N m}\left[R_{P 0 i}^{k}+\sum_{j=1}^{N m} k_{c M_{i}, j}^{k} C_{M i, a} \mu_{0, J}^{k}\right]$ \\
\hline $\begin{array}{l}\text { First-order; bulk polymer } \\
\text { moment }\end{array}$ & $R_{\lambda_{\delta_{i}}}=\sum_{i=1}^{N m} \delta(i-l)\left[R_{P 0 i}^{k}+\sum_{j=1}^{N m} k_{c M_{i}, j}^{k} C_{M i, a} \mu_{0, J}^{k}\right]+\sum_{i=1}^{N m} \sum_{j=1}^{N m} \delta(i-1) k_{p i j}^{k} C_{M i, a} \mu_{0, J}^{k}$ \\
\hline $\begin{array}{l}\text { Second-order; bulk polymer } \\
\text { moment }\end{array}$ & $R_{\lambda_{2}}=\sum_{K=1}^{N s} \sum_{j=1}^{N m}\left[R_{P 0 i}^{k}+\sum_{i=1}^{N m} k_{c M j, i}^{k} C_{M j, a} \mu_{0, i}^{k}\right]+\sum_{k=1}^{N s} \sum_{i=1}^{N m} \sum_{j=1}^{N m} k_{p j i}^{k} C_{M j, a}\left(\mu_{0, i}^{k}+2\right.$, \\
\hline
\end{tabular}

Bull. Chem. Soc. Ethiop. 2019, 33(1) 


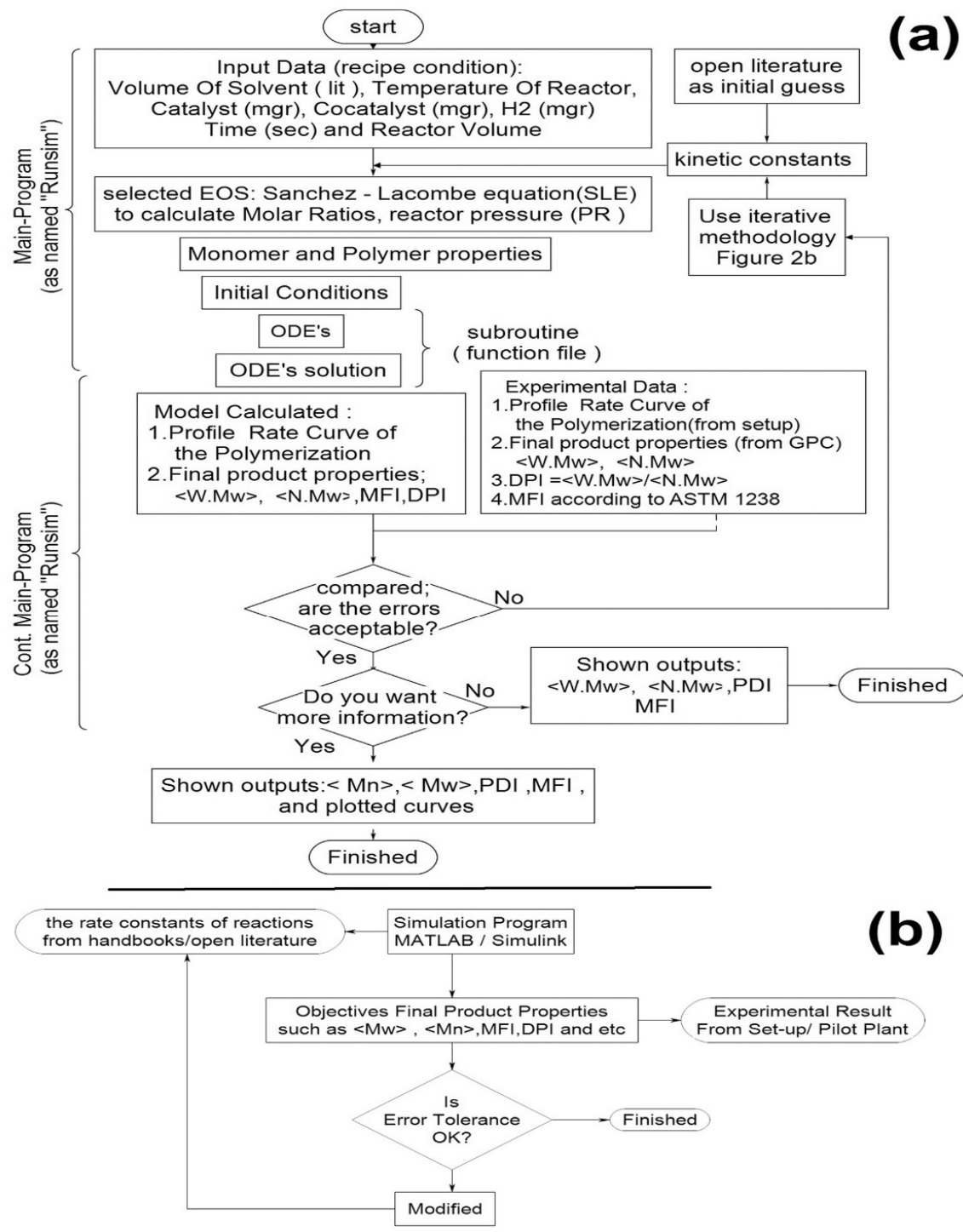

Figure 2. (a) The general algorithm modeling in this work; (b) The iterative methodology used for adjusting kinetic parameter in this work $[3,4]$.

\section{Modeling algorithm}

This study has outlined the algorithm for programming the mathematical model in a MATLAB/SIMULINK environment, as shown in Figure 2a. It is composed of two part; mainprogram (as named "Runsim") and subroutine (function file). For obtaining kinetic constants in the model, it is proposed a new approach as iterative method algorithm by using consistency property of ODE's equation in Figure $2 b$. 
In this study, from literature $[2,8]$, the initial guess of kinetic constants was estimated and applied to the model, next the constants were exactly adjusted and determined in accordance with the catalyst used in the set-up (experimental data ) by the proposed algorithm in Figure $2 \mathrm{~b}$. Comparing the polymerization profile rate of the model outputs and the experimental data in Figure $3 \mathrm{a}$ and $3 \mathrm{~b}$ implies that the fairly accurate kinetic constants have been adjusted and applied in the model.

\section{RESULTS AND DISCUSSION}

The aim of this study was to be established a validated model that it is able to predict the vital indices of final product properties such as number and weight average molecular weight (Mw and $\mathrm{Mn}$ ) and flow index (MFI); and also be able to determine the best process conditions of the polymerization recipe namely the reaction temperature and hydrogen amount in the polymerization system. For this purpose, a new model for the polymerization has been done by using population balance method to obtain directly the final product properties from kinetic equations. The model was coded in MATLAB/SIMULINK software program, according to the algorithm that shown in Figure 2a. The reaction equation used in the model is listed in Table 1 and the components rate and moment equation used in the model is summarized in Table 2.

One of the most important advantages of this model is that it is able to show the profile rate of the polymerization graphically, then it is possible to compare the model profile and the experimental profile rates come from the lab Set-up. By having the profile rate of the polymerization, it is easily possible to study the kinetics of the polymerization and also to determine the crucial indices belong to the kinetic study $[3,4]$. The experimental condition runs are listed under the title "recipe conditions" and also the results which come from the model and experimental are summarized in detail in Table 3.

The comparison between the model and experimental profile rates graphically at a different reaction temperature in the absence of hydrogen is shown in Figure 3a. The conclusions in this regard can be listed as follows: (1) The model profile rates are in line with the experimental profiles rates with a relatively acceptable error, it means that the model has been validated and adjusted kinetic parameter (constants) in a proper way manner by using the proposed algorithm in Figure 2b. In this regard, the other conclusion in this regard is that selected population balance approach is a suitable technique for the polymerization. (2) However, the error in modeling is inevitable; it can be explained by the source of error including the global numerical error that is the summation of truncation, method, and rounds off error; personal and systematic errors; the equation of state error; and the assumption errors.

Increasing reaction temperature gives rise to increase rate of reaction (obviously, according to Arrhenius equation). But rising the reaction temperature to $70{ }^{\circ} \mathrm{C}$ increases the catalyst yield and the average molecular weight (Figure 5a) and decreases polydispersity index (as favorite aspects); and from $70{ }^{\circ} \mathrm{C}$ to up, increasing temperature has exactly the opposite effect of these items (unfavorite aspects); refer to Table 3. It is concluded that the reaction temperature at $70{ }^{\circ} \mathrm{C}$ is the best condition in the absence of hydrogen in this study (run 3). Figure $3 b$ illustrates the comparison between the model profile rates and the experimental profiles rate at $70{ }^{\circ} \mathrm{C}$ in the absence of hydrogen in the polymerization system.

Hydrogen as chain transfer agent not only effects on final product properties but also has an influence on increasing activated site on the catalyst used and the kinetics of the polymerization as well. So far, three theories have been proposed to explain the influence of the hydrogen on polypropylene polymerization as follows: Theory 1: Increase in the number of active sites theory. Theory 2: The change in oxidation states theory. Theory 3: Dormant sites theory. 
Table 3. The comparison of model output and experimental results in different conditions.

\begin{tabular}{|c|c|c|c|c|c|c|c|c|c|c|}
\hline \multicolumn{6}{|c|}{ Recipe } & \multicolumn{5}{|c|}{$\begin{array}{c}\text { Results } \\
\text { ( Experimental/model) }\end{array}$} \\
\hline $\begin{array}{l}\text { Run } \\
\text { No. }\end{array}$ & $\begin{array}{c}\mathrm{T} \\
\left({ }^{\circ} \mathrm{C}\right)\end{array}$ & $\begin{array}{c}\mathrm{H}_{2} \\
(\mathrm{mg})\end{array}$ & $\begin{array}{c}\text { Molar } \\
\text { ratio } \\
\mathrm{X}=\mathrm{CH}_{2} / \\
\mathrm{Cm}\end{array}$ & $\begin{array}{c}\text { Catal } \\
\text { yst } \\
(\mathrm{mg})\end{array}$ & & $\begin{array}{c}\mathrm{Y} \\
(\mathrm{gr})\end{array}$ & $\begin{array}{l}<\mathrm{Mn} \\
>\end{array}$ & $\begin{array}{c}<\mathrm{Mw} \\
>\end{array}$ & $\begin{array}{c}\text { PD } \\
\mathrm{I}\end{array}$ & MFI \\
\hline \multirow{2}{*}{1} & \multirow{2}{*}{65} & \multirow{2}{*}{0} & \multirow{2}{*}{0} & \multirow{2}{*}{20} & $\begin{array}{l}\text { Experimental } \\
\text { result }\end{array}$ & $\begin{array}{l}63 . \\
29\end{array}$ & $\begin{array}{c}2102 \\
59\end{array}$ & $\begin{array}{c}86305 \\
7\end{array}$ & 4.1 & 0.75 \\
\hline & & & & & Model result & $\begin{array}{c}65 . \\
13\end{array}$ & $\begin{array}{c}2055 \\
70\end{array}$ & $\begin{array}{c}83452 \\
3\end{array}$ & $\begin{array}{c}4.0 \\
6\end{array}$ & 0.81 \\
\hline \multirow{2}{*}{2} & \multirow{2}{*}{70} & \multirow{2}{*}{0} & \multirow{2}{*}{0} & \multirow{2}{*}{20} & $\begin{array}{c}\text { Experimental } \\
\text { result }\end{array}$ & $\begin{array}{l}72 . \\
66\end{array}$ & $\begin{array}{c}3046 \\
42\end{array}$ & $\begin{array}{c}11343 \\
74\end{array}$ & $\begin{array}{c}3.7 \\
1\end{array}$ & 0.42 \\
\hline & & & & & Model result & $\begin{array}{c}76 . \\
4\end{array}$ & $\begin{array}{c}3237 \\
80\end{array}$ & $\begin{array}{c}12144 \\
40\end{array}$ & $\begin{array}{c}3.7 \\
5\end{array}$ & 0.33 \\
\hline \multirow{2}{*}{3} & \multirow{2}{*}{75} & \multirow{2}{*}{0} & \multirow{2}{*}{0 . } & \multirow{2}{*}{20} & $\begin{array}{c}\text { Experimental } \\
\text { result }\end{array}$ & $\begin{array}{c}63 . \\
07\end{array}$ & $\begin{array}{c}2361 \\
54 \\
\end{array}$ & $\begin{array}{c}11243 \\
67 \\
\end{array}$ & $\begin{array}{c}4.7 \\
6 \\
\end{array}$ & 0.4 \\
\hline & & & & & Model result & $\begin{array}{l}67 . \\
25\end{array}$ & $\begin{array}{c}2702 \\
43\end{array}$ & $\begin{array}{c}11783 \\
00\end{array}$ & $\begin{array}{c}4.3 \\
6 \\
\end{array}$ & 0.36 \\
\hline \multirow[b]{2}{*}{4} & \multirow[b]{2}{*}{70} & \multirow[b]{2}{*}{18} & \multirow[b]{2}{*}{0.00466} & \multirow[b]{2}{*}{10} & $\begin{array}{c}\text { Experimental } \\
\text { result }\end{array}$ & $\begin{array}{l}81 . \\
33\end{array}$ & $\begin{array}{c}2996 \\
2 \\
\end{array}$ & $\begin{array}{c}14419 \\
2 \\
\end{array}$ & $\begin{array}{c}4.8 \\
1 \\
\end{array}$ & 37 \\
\hline & & & & & Model result & $\begin{array}{c}88 . \\
4\end{array}$ & $\begin{array}{c}3281 \\
2.7\end{array}$ & $\begin{array}{c}14887 \\
4\end{array}$ & $\begin{array}{c}4.5 \\
4\end{array}$ & $\begin{array}{c}36.9956 \\
2\end{array}$ \\
\hline \multirow{2}{*}{5} & \multirow{2}{*}{70} & \multirow{2}{*}{27} & \multirow{2}{*}{0.00703} & \multirow{2}{*}{10} & $\begin{array}{c}\text { Experimental } \\
\text { result }\end{array}$ & $\begin{array}{l}74 . \\
61 \\
\end{array}$ & $\begin{array}{c}2401 \\
6 \\
\end{array}$ & $\begin{array}{c}11693 \\
9 \\
\end{array}$ & $\begin{array}{c}4.8 \\
7 \\
\end{array}$ & 62 \\
\hline & & & & & Model result & $\begin{array}{l}76 . \\
81\end{array}$ & $\begin{array}{c}2498 \\
1.1\end{array}$ & $\begin{array}{c}12330 \\
3 \\
\end{array}$ & $\begin{array}{c}4.9 \\
4\end{array}$ & $\begin{array}{c}61.9862 \\
7\end{array}$ \\
\hline \multirow{2}{*}{$6^{1}$} & \multirow{2}{*}{70} & \multirow{2}{*}{2000} & \multirow{2}{*}{0.0206} & \multirow{2}{*}{10} & $\begin{array}{c}\text { Experimental } \\
\text { result }\end{array}$ & & & & & 650 \\
\hline & & & & & Model result & $\begin{array}{l}64 . \\
92\end{array}$ & $\begin{array}{c}9952 . \\
25\end{array}$ & $\begin{array}{c}70163 \\
.4\end{array}$ & $\begin{array}{c}7.0 \\
6\end{array}$ & 670.59 \\
\hline \multirow{2}{*}{$7^{1}$} & \multirow{2}{*}{70} & \multirow{2}{*}{2500} & \multirow{2}{*}{0.0243} & 10 & $\begin{array}{c}\text { Experimental } \\
\text { result }\end{array}$ & & & & & 900 \\
\hline & & & & 10 & Model result & $\begin{array}{l}61 . \\
26\end{array}$ & $\begin{array}{c}8353 . \\
86\end{array}$ & $\begin{array}{c}61651 \\
.5\end{array}$ & $\begin{array}{c}7.3 \\
8\end{array}$ & 925.20 \\
\hline
\end{tabular}

X: Hydrogen molar ratio, it is calculated by Aspen Software polymer software based on SLE (SOE). ${ }^{1}$ as the product was off or wax grade only MFI of product was measured 3.
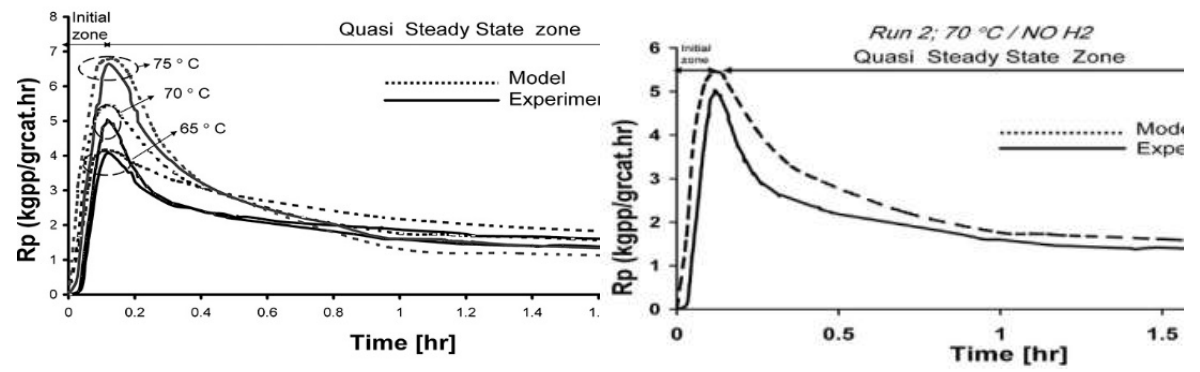

Figure 3. (a) The comparison of the experimental and model out of the profile rate in the absence of hydrogen at a different temperature. (b) The comparison of the experimental and model out of the profile rate in the absence of hydrogen at the constant temperature of $70{ }^{\circ} \mathrm{C}$.

Bull. Chem. Soc. Ethiop. 2019, 33(1) 
So far, the first and second theories studies have been rejected and the reasons for the rejection of theories exist in the open literature [14]. For the sake of brevity, the detailed discussion in this regard is avoided in this paper. But it should be mentioned that the dormant sites theory is still the strongest theory in this field. The comparison between the model and experimental profile rates graphically at a different hydrogen amount in the polymerization system at the constant reaction temperature of $70^{\circ} \mathrm{C}$ is shown in Figure 4a.

Before proceeding to discuss the effect of hydrogen on the polymerization, it is necessary to remark that as mass flow controller (MFC) of lab setup shows the amounts of hydrogen which are entered to the reactor as per milligram, firstly the amounts were listed as per [mg] in Table 3 . Then their equivalents in molar ratio were inserted in a separated column in front of them. Molar Ratio was calculated by ASPEN Software based on Sanchez and Lacombe Equation (SLE).

As can be seen from Figure 4a, it is concluded that increasing hydrogen amount leads to increase the rate of reaction and the reason for this event can be explained by dormant sites theory. The theory says hydrogen causes to raise the activated site on the catalyst used. The quality and quantity of this event on the catalyst used have been modeled in previous work [3]. The results belong to runs 2, 4 and 5 from Table 3 show that rising hydrogen amount to $18 \mathrm{mg}$ gives rise to increase rate of the polymerization, the catalyst yield and reduces the average molecular weight to allowance limit ( and also Figure $5 \mathrm{~b}$ ) and decreases polydispersity index (as favorite aspects); and from $18 \mathrm{mg}$ to up, increasing hydrogen amount not only decreases rate of polymerization but also has exactly the opposite effect of these items except average molecular weight to reduce more to make product as off grade (as unfavorite aspects). It is concluded that the hydrogen amount at $18 \mathrm{mg}$ at the constant temperature $\left(70{ }^{\circ} \mathrm{C}\right)$ is the best condition in this study (run 4). Figure $4 \mathrm{~b}$ illustrates the comparison between the model profile rates and the experimental profiles rate at $70{ }^{\circ} \mathrm{C}$ and hydrogen amount at $18 \mathrm{mg}$ in the polymerization system.
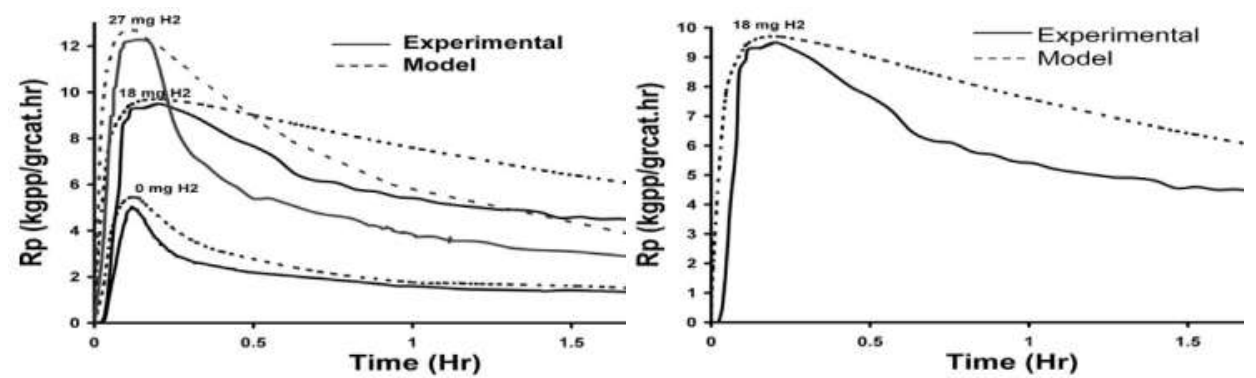

Figure 4. (a) The comparison of the experimental and model out of the profile rate at a different hydrogen amount and the constant temperature of $70{ }^{\circ} \mathrm{C}$ (b) The comparison of the experimental and model out of the profile rate at $18 \mathrm{mg}$ hydrogen amount and the constant temperature of $70^{\circ} \mathrm{C}$.

Figure $5 \mathrm{~b}$ shows changing the average molecular weight by increasing hydrogen amount in the polymerization system, from point A to B, the functionality of hydrogen is as chain transfer agent reacts with the active site on the chain, therefore, hydrogen causes to terminate the growth of the polymer chain then the average molecular weight is decreased; afterward from $\mathrm{B}$ to $\mathrm{C}$ excess hydrogen amount reacts with the activated site on the catalyst surface and for that reason the rate of the polymerization and the yield of the catalyst also decrease slightly. 

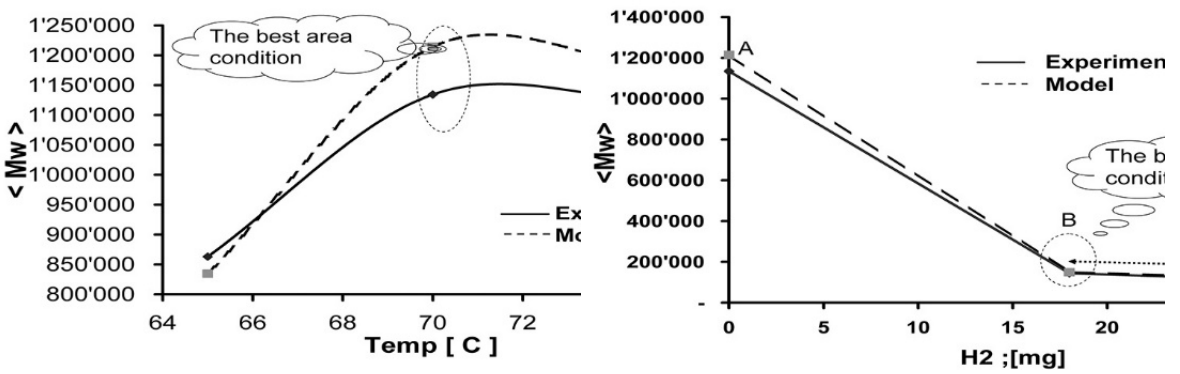

Figure 5. (a) The comparison of the experimental and model outputs of the average molecular weight of the polymer in the absence of hydrogen at different temperatures. (b) The comparison of the experimental and model outputs of the average molecular weight of the polymer in the presence of different hydrogen concentration at the constant temperature of $70^{\circ} \mathrm{C}$.

As melt flow index (MFI) is one of the vital rheology indexes, in this study, it is concluded that in absence of hydrogen, the melt flow index (MFI) might be a function of average molecular weight (Mw) and obeys from the power-law-equation based on MarkHouwink model, i.e. equation (5). The constants of $\mathrm{a}$ and $\mathrm{b}$ were obtained as $\mathrm{a}=9.4841 \times 10^{13}$ and $b=-2.3747$ with a linear correlation coefficient $\left(\mathrm{R}^{2}\right)$ of 0.99 [3]. It is concluded that increasing reaction temperature to $70{ }^{\circ} \mathrm{C}$ leads to decreasing MFI according to the same aforementioned reasons for $\mathrm{Mw}$; but after $70{ }^{\circ} \mathrm{C}$, MFI increase by increasing the reaction temperature. Therefore MFI has a minimum point at $70{ }^{\circ} \mathrm{C}$ in the absence of hydrogen, as shown in Figure 6.

In contrast, in presence of hydrogen, the Mark-Houwink model does not predict MFI correctly; according to McAuley and MacGregor's comments for polyethylene and Wang's opinion for polypropylene, the melt flow index (MFI) is a function of reaction temperature and hydrogen concentration in the system. Given this orientation, equation (7) was considered as a suitable model to calculate and predict of MFI in presence of hydrogen. For this study as shown in Figure $7 \mathrm{a}$, the $\alpha, \beta$, and $\gamma$ of equation (4) were fitted and obtained with a correlation coefficient $\left(\mathrm{R}^{2}\right)$ of 0.98 as follows: $\alpha=13.42, \beta=1.948$ and $\gamma=-3.756$.

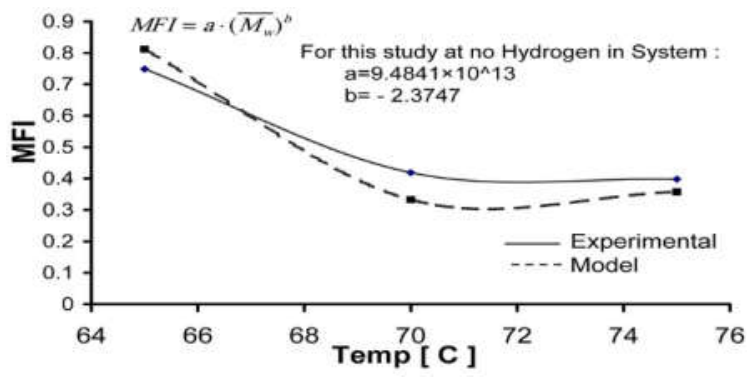

Figure 6. The variation of MFI with the reaction temperature changes and the constant temperature of $70^{\circ} \mathrm{C}$.

Figure $7 \mathrm{a}$, shows the variation of MFI with hydrogen changes and the constant temperature of $70{ }^{\circ} \mathrm{C}$. Within the scope of this research, the model curve with the experimental curve is completely consistent as shown in Figure $7 \mathrm{~b}$. 

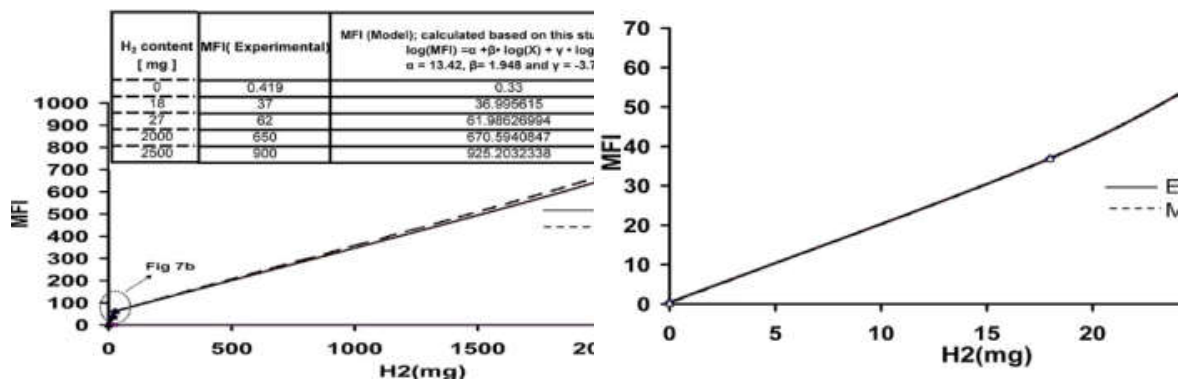

Figure 7. (a) The variation of MFI with hydrogen changes and the constant temperature of 70 ${ }^{\circ} \mathrm{C}$. (b) The variation of MFI with hydrogen changes and the constant temperature of $70^{\circ} \mathrm{C}$ within the scope of this research.

\section{CONCLUSION}

In this work, a validated model is presented which is able to calculate and show graphically the profile rate of propylene polymerization. In this paper, the comparisons between the profile rates come from the experimental and model output have been down. It is concluded that the model profile rates are in line with the experimental profiles rates with a relatively acceptable error and also concluded that the selected approach is a suitable technique for this study; the model was tuned in a proper way by the proposed algorithm. The software program was coded in MATLAB/SIMULINK and validated by the experimental data come from a lab setup reactor.

In addition, the variation of the melt flow index in the absence and the presence of hydrogen were investigated and concluded that MFI only obeys from the power-law-Equation based on Mark-Houwink model in absence of hydrogen. A new model for MFI as a function of the reaction temperature and the hydrogen amount was proposed and the constants of the model were determined and shown that the proposed model has an acceptable performance in this study. Finally, it is concluded that the reaction temperature at $70{ }^{\circ} \mathrm{C}$ and hydrogen amount at $18 \mathrm{mg}$ could be considered as the best process condition in this study. It is suggested that to be investigated in this field of the catalyst deactivation model and also the average molecular weight distribution for future studies.

\section{Notation}

total active site concentration,

C $\quad \mathrm{kgmol} / \mathrm{m}^{3}$

$C_{d} \quad$ dead-site concentration, $\mathrm{kgmol} / \mathrm{m}^{3}$ component $j$ bulk concentration,

Cj $\mathrm{kgmol} / \mathrm{m}^{3}$ concentration into the reactor,

$C j, R \quad \mathrm{kgmol} / \mathrm{m}^{3}$ type $k$ active specie concentration,

Ck $\mathrm{kgmol} / \mathrm{m}^{3}$ potential site concentration,

Cp $\quad \mathrm{kgmol} / \mathrm{m} 3$

dead polymer chain concentration with $\boldsymbol{n}$ monomers originated from

$D k n \quad$ site $k, \mathrm{kgmol} / \mathrm{m} 3$

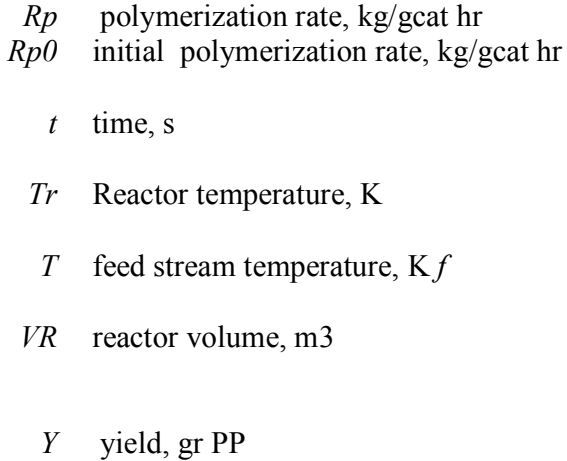




$\begin{aligned} \text { DPI } & \begin{array}{l}\text { polydispersity index } \\ \text { two-site equilibrium constant, } \\ \text { kgmol }^{-1} \\ \text { mass average molecular weight, } \\ \text { kg/kgmol }\end{array} \\ N C & \text { number of liquid-phase components } \\ n j, R & \begin{array}{l}\text { kgmoles of component } j \text { into reactor, } \\ \text { kgmoles of } j \text { sorbed in the amorphous }\end{array} \\ n j, a & \begin{array}{l}\text { polymer phase, kgmol } \\ \text { moles of } j \text { in the liquid phase },\end{array} \\ n j, l & \begin{array}{l}\text { kgmol } \\ \text { number of monomers } \\ \text { number of sites } \\ \text { order of reaction } r \text { for site } k \\ \text { growing polymer chain with } \boldsymbol{n} \\ \text { monomers with end-group } i \text { from } \\ \text { site } k, \text { kgmol/m3 }\end{array}\end{aligned}$

$r$ reaction from site $k$ for a growing chain with $\boldsymbol{n}$ monomers, $\mathrm{kgmol} /(\mathrm{s}$.

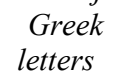

equilibrium constant for $j$ component between liquid phase and amorphous $\Gamma j$ polymer phase ratio between solid-phase components concentration at reactor output flow

$\Xi$ and into reactor ratio between liquid-phase components concentration at reactor

$H$ output flow and into reactor volume fraction of monomer in the

$X$ amorphous polymer phase

$P l \quad$ liquid-phase density, kgrm3

$\rho p$ polymer density, $\mathrm{kg} / \mathrm{m} 3$

$\rho R$ reactor slurry density, kgrm3

$\mu$ Live moment rate Equations

\section{REFERENCES}

1. Busico, V.; Cipullo, R.; Mingione, A.; Rongo, L. Accelerating the research approach to Ziegler-Natta catalysts. Ind. Eng. Chem. Res. 2016, 55, 2686-2695.

2. Reginato, A.S.; Zacca, J.J.; Secchi, A.R. Modeling and simulation of propylene polymerization in nonideal loop reactors. AIChE J. 2003, 49, 2642-2654.

3. Varshouee, G.H.; Heydarinasab, A.; Vaziri, A.; Roozbahani, B. Hydrogen effect modeling on Ziegler-Natta catalyst and final product properties in propylene polymerization. Bull. Chem. Soc. Ethiop. 2018, 32, 371-386.

4. Varshouee, G.H.; Heydarinasab, A.; Vaziri, A.; Roozbahani, B. Determining final product properties and kinetics studies of polypropylene polymerization by a validated mathematical model. Bull. Chem. Soc. Ethiop. 2018, 32, 579-594

5. Al-haj, A.M.; Betlem, B.; Roffel, B.; Weickert G. Hydrogen response in liquid propylene polymerization: Towards a generalized model. AIChE J. 2006, 52, 1866-1876.

6. Pater, J.T.M.; Weickert, G.; van Swaaij, W.P.M. Polymerization of liquid propylene with a fourth generation Ziegler-Natta catalyst: Influence of temperature, hydrogen, monomer concentration, and prepolymerization method on polymerization kinetics. J. App. Polym. Sci. 2003, 87, 1421-1435.

7. Shimizu, F.; Pater, J.T.M.; Van Swaaij, W.P.M. Weickert G. Kinetic study of a highly active $\mathrm{MgCl}_{2}$-supported Ziegler-Natta catalyst in liquid pool propylene polymerization. II. The influence of alkyl aluminum and alkoxysilane on catalyst activation and deactivation. $J$. App. Polym. Sci. 2002, 83, 2669-2679.

8. Luo, Zh.H.; Zheng, Y.; Cao, Z.K.; Wen, S.H. Mathematical modeling of the molecular weight distribution of polypropylene produced in a loop reactor. Poly. Eng. Sci. 2007, 47, 1643-1649. 
9. Chatzidoukas, C.; Perkins, J. D.; Pistikopoulos, E. N.; Kiparissides, C. Optimal grade transition and selection of closed-loop controllers in a gas-phase olefin polymerization fluidized bed reactor. Chem. Eng. Sci. 2003, 58, 3643-3658.

10. Samson, J.J.C.; Bosman, J.B.; Weickert, G.; Westerterp, K.R. Liquid-phase polymerization of propylene with a highly active Ziegler-Natta catalyst: Influence of hydrogen, cocatalyst, and electron donor on reaction kinetics. J. Polym. Sci. Part A: Polym. Chem. 1999, 37, 219232.

11. Yuan, H.G.; Taylor T.W.; Choi K.Y.; Ray, W.H. Polymerization of olefins through heterogeneous catalysis. 1. Low-pressure propylene polymerization in slurry with ZieglerNatta catalyst. J. Appl. Polym. Sci. 1982, 27, 1691-1706.

12. Zhu, Y.P.; Luo, Z.H.; Xiao, J.; Multi-scale product property model of polypropylene produced in a FBR: From chemical process engineering to product engineering. Comput. Chem. Eng. 2014, 71, 39-51.

13. Kim, S.H.; Baek, S.W.; Lee, J.C.; Lee, W.J.; Hong, S.U.; Oh, M. Dynamic simulation of liquid polymerization reactors in Sheripol process for polypropylene. J. Ind. Eng. Chem. 2016, 33, 298-306.

14. Costa, G.M.N.; Kislansky, S.; Oliveira, L.C.; Pessoa, F.L.P.; Vieira de Melo, S.A.B.; Embiruc M. Modeling of solid-liquid equilibrium for polyethylene and polypropylene solutions with equations of state. J. Appl. Polym. Sci. 2010, 121, 1832-1849.

15. Spitz, R.; Masson, P.; Bobichon, C.; Guyot, A. Activation of propene polymerization by hydrogen for improved $\mathrm{MgCl}_{2}$-supported Ziegler-Natta catalysts, Makromol. Chem. 1989, 190, 717-723.

16. McAuley, K.B.; MacGregor, J.F. On-line inference of polymer properties in an industrial polyethylene reactor. AIChE J. 1991, 37, 825-835.

17. Wang, Y.; Seki, H.; Ohyama, S.; Ogawa, M.; Ohshima, M. Optimal grade transition control for polymerization reactors. Comput. Chem. Eng. 2000, 24, 1555-1561. 